\title{
Energy efficiency behaviour in the built environment - an assessment of current evaluation practices in the Nordic countries
}

\author{
Maria Johansson (iD) N Niko Gentile • Lena Neij
}

Received: 9 July 2019 / Accepted: 29 January 2021 / Published online: 22 February 2021

(C) The Author(s) 2021

\begin{abstract}
Behavioural change is expected to play a significant role in the transformation to a more energy efficient built environment. Despite this, current evaluation practice of interventions often overlook behavioural aspects in their ambition of advancing our knowledge on transformative change. Moreover, little attention is paid to how different research perspectives on human behaviour can complement each other in providing a broader scope and deeper understanding of behavioural change. In this study, we acknowledge this gap, and assess the current evaluation practices on behaviour. The focus is on energy efficiency in the built environment in the Nordic countries, and evaluations undertaken by researchers. The assessment shows that the Nordic evaluations apply a variety of disciplinary approaches, but have only to a limited extent addressed a psychological understanding of individual behaviour and
\end{abstract}

M. Johansson $(\bowtie)$

Environmental Psychology, Department of Architecture and the

Built Environment, Lund University, P.O. Box 118, SE-221

00 Lund, Sweden

e-mail: maria.johansson@mpe.lth.se

N. Gentile

Energy and Building Design, Department of Architecture and the Built Environment, Lund University, P.O. Box 118, SE-221

00 Lund, Sweden

e-mail: niko.gentile@ebd.lth.se

L. Neij

International Institute for Industrial Environmental Economics (IIIEE), Lund University, P.O. Box 196, SE-221 00 Lund, Sweden e-mail: lena.neij@iiiee.lu.se behavioural change. We analyse and discuss the potential contribution of environmental psychology in strengthening a cross disciplinary evaluation approach. In all, the results indicate the value of also adding environmental psychology, to provide a stronger cross disciplinary understanding of behavioural change, and the need to coordinate and combine evaluations departing from different disciplinary approaches, to improve understanding of the transformational process.

Keywords Energy efficiency · Built environment Evaluation - User behaviour · Environmental psychology

\section{Introduction}

Energy efficiency in the built environment can make significant contributions to the urgent need for a transformative change towards a more sustainable society. Energy efficiency will improve resource efficiency and is an important measure to meet goals relating to climate change, energy security, energy poverty and environmental degradation (GEA 2012; IEA 2018). The built environment accounts for approximately $32 \%$ of the global final energy use and $19 \%$ of energy-related greenhouse gas emissions (Lucon et al. 2014). The potential for energy efficiency and for reducing energy demand has been estimated at 50-75\% in existing buildings and 50-90\% in new buildings, including changes in design practices, technology and behaviour (Lucon et al. 2014). 
Over the years, various energy interventions have been implemented to support a transformative change in the energy system and to utilise the potential of energy efficiency in the built environment, but with limited success. In this paper, we argue that such a transformative change will require evaluations that go beyond the evaluation practice of today to provide necessary learning from actions taken, and that there is a need to improve our understanding the social and behavioural potentials for energy efficiency in such evaluations. Moreover, the knowledge required cannot rely on one single discipline but will require the integration of knowledge from multiple disciplines (Stern 2014, 2017).

The research presented in this paper is part of a cross disciplinary project on transformative evaluation of initiatives for energy efficiency in the built environment in Sweden (Neij et al. 2021). The preceding analyses on evaluations of policy programmes show that the behavioural potentials are treated in a rudimentary way or completely overlooked (Sandin et al. 2019). Based on these results, the aim of this paper is to advance the understanding and assessment of behaviour in the transformation to a more energy efficient built environment. The analyses focuses on how current evaluation practice of interventions in the Nordic countries introduced to obtain behavioural change could be broadened by adding an environmental psychology perspective.

Social science perspectives on energy efficiency behaviour

An increasing interest in non-technical dimensions of energy and building research has been observed, but the research often presents a narrow understanding of the social aspects under study (Schweber and Leiringer 2012). This is reflected in a review of 4444 research papers on energy efficiency, where only $19.6 \%$ of authors report training in social science disciplines (Sovacool 2014). Only 2.2\% of the articles reviewed by Sovacool (2014) concern end-use behaviour. The international literature on energy efficiency behaviour has been criticised for deploying positivist versus interpretivist approaches in the analysis of people's behaviour (Keller et al. 2016). Moreover, methods are inadequately used when transferred between approaches, as an example interviews are used to produce information and facts that are measurable, and financial data has been applied to model social behaviour (Schweber and Leiringer 2012).

Internationally, current social science research on energy efficiency behaviour is predominantly based on economics, sociology and psychology, although other disciplines are reported, such as geography and anthropology (Keller et al. 2016). The behavioural potential has sometimes been limited to economics (Stern 2017) or a rational choice perspective with a point of departure based on attitude theory with a focus on linking information, knowledge, attitudes and individual choice, combined with expectations that monetary savings and moral benefits would be sufficient to motivate behavioural change (Moezzi and Janda 2014).

However, an examination of processes, meaning, understandings and motivations that produce observed patterns and systems is also needed (Schweber and Leiringer 2012). This is argued in, for example, social practice theory, which has been suggested as a way of understanding the social context (Shove 2010; Hargreaves 2011), and opening for a social potential in supporting energy efficiency (Moezzi and Janda 2014). We support the idea that different research perspectives on human behaviour complement each other, and that integrative perspectives are needed (Bögel and Upham 2018; Chatterton and Wilson 2013; Lenoir-Improta et al. 2017; Wilson and Chatterton 2011).

Energy efficiency behaviour in Nordic studies

In the Nordic countries, energy efficiency behaviour is studied from a wide variety of disciplines, ranging from technology, environmental sciences, architecture, economics, psychology, geography, sociology and sciencetechnology studies. In contrast to other parts of Europe and the USA for example, in the Nordic countries the investigation of the role of humans and human behaviour in energy efficiency has long been studied from traditional sociological perspectives, including powerrelations and gender-related issues (Carlsson-Kanyama and Lindén 2007; Lindén 2001). In recent years, there has also been a strong focus on social practice theory (e.g. Gram-Hanssen et al. 2007, Gram-Hanssen 2010), but the psychological perspective focusing on individual aspects of behaviour and/or behavioural change has had a marginalised role (Johansson and Neij 2017). Internationally, environmental psychology has been proposed to be a potent tool in understanding human behaviour and drivers and barriers for behavioural change towards 
sustainability (Amel et al. 2017). In practice, this means that among Swedish evaluations of policy programs on energy efficiency, the rare evaluations that do consider behavioural outcomes still lack the local contextual understanding of the psychological factors associated with behavioural outcomes (Sandin et al. 2019).

\section{Objective}

In this paper, we argue that various research perspectives on human behaviour can complement each other providing a broader scope and deeper understanding of behavioural change. The question is what the potential contribution of environmental psychology might be in strengthening a cross-disciplinary approach to evaluation of energy efficiency interventions in the built environment in the Nordic countries. The specific objective is to identify the extent to which and how environmental psychology could strengthen the current practice in evaluating energy efficiency behaviour in the Nordic countries. This is done by (a) identifying key questions for evaluations of energy efficiency behaviour from environmental psychology theory, (b) applying these questions in the analyses of empirical studies spanning disciplinary approaches of evaluating energy efficiency behaviour in a Nordic context and (c) identifying how the key questions are considered (or not considered) in current Nordic research on energy efficiency behaviour.

This paper discusses the evaluation of behaviour and behavioural change in response to interventions in the Nordic countries aiming at energy efficiency behaviour. Although there are many differences between the Nordic countries, they are, in a global perspective, similar. These countries largely share climate conditions, with long, dark and cold winter seasons, and building standards regarding indoor heating and insulation are high. Despite strong efforts in reducing energy usage through building practice and technological developments in the Nordic countries, there are substantial gaps between estimated and measured energy usage, the major causes being household practices and people's behaviour (e.g. Gram-Hanssen 2014; Hiller 2020)

The analysis is carried out on two groups of common interventions in the Nordic context: interventions based on providing users with information and/or feedback, and interventions based on providing building design as a tool to improve energy efficiency in buildings. These interventions were chosen because they rely on two different main strategies for behavioural change, described in more detail below. This article outlines as follows: in "Theory: an environmental psychology approach, key perspectives and questions" section, we present key perspectives and questions in environmental psychology; in "Material and methods" section, we present the material and methods used in the study to asses to what extent these perspectives and questions are captured in evaluations presented in scientific peerreviewed papers on energy efficiency behaviour in the built environment; and in "Results - empirical test of identified questions", "Discussion" and "Conclusions" sections, we present and discuss the results.

\section{Theory: an environmental psychology approach, key perspectives and questions}

Environmental psychology stems from the recognition that human behaviour is central in many environmental problems, so solutions must be sought in human behaviour. The discipline is widely applied and is based on real-world problems. Environmental psychology applies a holistic approach to understanding humanenvironment transactions, that is the psychological processes in the interplay between people and their surroundings. The focus is on the individual, as an integrated part of the social and physical environmental setting (Gifford 2014). Individual's behaviour is understood as the outcome of an interplay between individual characteristics (e.g. sociodemographics, personality, and personal values, attitudes and norms) and the surrounding physical and social environment.

A person's behaviour may differ between activities and situations. A fundament is that the individual's appraisal of the social and physical-spatial aspects in people's daily lives must be considered if we are to understand human behaviour (e.g. Gifford 2014; Küller 1991; Nasar 2008), including the potential effect of interventions for behavioural change (Steg and Vlek 2009). Environmental psychology may help to strengthen current evaluation practice by applying an in-depth understanding of energy efficiency behaviour, antecedents of such behaviour and the underlying psychological process activated by an intervention in the change towards more energy efficient behaviour (Gifford and Nilsson 2014; Huijts et al. 2012; Steg 2008; Steg et al. 2015; Stern 2014). In an evaluation perspective, this can be done by (1) strengthening the (theoretical) focus (on behavioural aspects) of the evaluation, (2) considering 
how research design and methodology are used as tools in the evaluation to address behavioural aspects and (3) checking for the alignment between chosen focus and tools in the evaluation. Each one of these steps are further discussed in the text below and the corresponding evaluation questions are formulated and summarized in Table 1.

Strengthening the focus on behaviour of the evaluation: choice of intervention, definition of target behaviour and the drivers (antecedents) considering the context

An understanding is needed of what psychological process the chosen intervention strategy is thought to activate behavioural change, and the behaviour to be targeted must be defined. Interventions to bring about behavioural change to reduce energy use in buildings can be based on several strategies. From an environmental psychology perspective, an important distinction is between structural strategies and psychological strategies. Structural strategies draw on external incentives that make behaviour with negative environmental impact more costly and behaviour with positive

Table 1 Overview of questions derived from environmental psychology regarding the focus and tools used in evaluations of energy efficiency behaviour. In "Material and methods" section,

ALIGNMENT - How is

the focus and tools employed aligned?
FOCUS

Intervention

Behaviour

Context

TOOLS

Theory

Research design

Methods environmental impact less costly through, for example, subsidies. Psychological strategies aim to enhance the personal motivation to engage in pro-environmental behaviour (Steg et al. 2015).

Another distinction made in the psychological strategies is between antecedent interventions and consequence strategies. Antecedent interventions are aimed at influencing underlying behavioural determinants, so called antecedents, which in turn are believed to influence behaviour (for example information, rolemodelling of behaviour, commitments, goal setting and prompts). Consequence strategies are based on the assumption that the presence of positive or negative consequences will influence behaviour, for example individual or comparative feedback and rewards (Abrahamse et al. 2005; Dwyer et al. 1993; Steg et al. 2015). These have also been termed soft policy measures (Schuitema and Bergstad Jakobsson 2013).

The likelihood that the expected behavioural change resulting from an intervention will occur may depend on whether the intervention suits the individual, whether it matches the type of behaviour (Gardner and Stern 1996; Schuitema and Bergstad Jakobsson 2013; Stragier et al.

these questions are used to structure the assessment of to what extent environmental psychology is captured, or could further complement and support current evaluation practice.

\section{Key questions}

How is the intervention selected defined and described? How is the intervention intended to activate the psychological process of behavioural change in the target behaviour?

How is the behaviour under study defined? Does the operationalisation reflect a behaviour or a perception?

Are spill-over effects of the behaviour considered?

Does the behaviour persist over time?

What are the considerations of potential antecedent factors to the behaviour studied?

How are antecedents defined and operationalised?

Is the social context of the behaviour described?

Is the physical context of the behaviour described?

How are individual and social characteristics of the target group described?

Key questions

Is the study based on theory related to human behaviour and/or behavioural change?

Does the research design allow for understanding/evaluation of behaviour /behavioural change?

What method is used to capture behaviour?

Does the employed method capture individual antecedents?

Does the employed method capture social and environmental contextual factors? 
2012), the current stage of the individual's behaviour (Geller 2002) and the extent to which the behavioural change is supported by contextual factors, (Chatterton and Wilson 2013; Dietz et al. 2013; Geller 2002). This undoubtedly implies that the target behaviour must be defined, to enable assessment of the potential of the intervention available. In evaluations of effects of interventions on people's energy use behaviour, the relationship between different behaviours should be considered, as there may be spill-over effects, both positive and negative (Steg et al. 2015). The consequences of a behaviour change should also be considered in terms of its broader implications for daily stress, quality of life and well-being (Moser 2009). These effects should ideally be considered in both the short and long terms.

People's engagement in energy efficiency behaviour is not just limited to instrumental factors, e.g. costs and benefits in terms of price, time and comfort. Research reviews on antecedents investigated in relation to proenvironmental behaviour in general, as well as more specifically in relation to energy efficiency behaviour, suggest that attention should be paid to individual as well as social factors (for extensive reviews see Gifford and Nilsson 2014; Steg et al. 2015). These reviews suggest that at the individual level sociodemographics, knowledge and education are often investigated. A certain level of awareness of the relation between personal behaviour and an environmental problem has been shown to be necessary but not sufficient for behavioural change. The effect of gaining in-depth knowledge will be limited when people are not motivated or when they do not feel able to engage in the pro-environmental behaviour. Further understanding of what motivates pro-environmental behaviour may be gained by addressing personality and personal values. Certain personality traits e.g. openness to experience, agreeableness and conscientiousness have been found to be related to pro-environmental behaviour. An internal locus of control, i.e. to perceive events to be controlled by one's own behaviour or personal characteristics, and selfefficacy i.e. a belief in one's capabilities to organize and execute actions required to manage a situation, have been identified to facilitate engagement in proenvironmental behaviour. Also, the personal relationship with the environment expressed as a feeling of being fundamentally interconnected with all living things seem to matter. People's basic values serve as guiding principles in life. People who hold values that orient towards self-transcendence, i.e. values that goes beyond egoistic concerns, and care about other people (altruistic values) and the environment (biospheric values). Further, post-materialist values, usually found among people with the basic materials of life satisfied, and associated with "higher-level" goals and actions may facilitate engagement in pro-environmental behaviour. More specifically political views and how people think about nature have also been suggested as antecedents of pro-environmental behaviour. Individual factors of importance may also be situationally bound in time and context: engagement in outdoor activities, especially non-consumptive ones such as appreciation of nature; place attachment, if people have a strong emotional connection to a place, especially the natural aspects of a place, then the individual is more likely to want to protect it; and feelings of responsibility for the environment. Personal goals to engage in pro-environmental behaviour may also serve as additional motivators.

Social antecedents of pro-environmental behaviour are found in the individual's daily life in terms of religion and social class, and identification with urban versus rural contexts, but with inconclusive outcomes in terms of pro-environmental behaviour. The proximity to problem sites shows consistent results, in that people who live closer to a problem site are more concerned. Norms constitute a powerful antecedent to behaviour. Norms comes in many shapes and can be further divided into personal norms representing one's feelings of moral obligation towards taking action, and subjective norms representing one's sense that significant others expect a certain pattern of behaviour. Moreover, norms are inferred from what others do or do not do. In particular, prescriptive norms (conveying what behaviour is expected) and injunctive norms (conveying social approval or disapproval of behaviour) are associated with pro-environmental behaviour. Status may also motivate proenvironmental behaviour in the sense that a behaviour that is financially expensive to undertake can give off positive symbolic signals by indicating that the individual has sufficient resources to make altruistic sacrifices.

Attention to potential individual and social antecedents of energy use behaviour in the evaluation practice is important for two reasons. It can help formulate questions that consider the characteristics of the target group investigated, and questions regarding the antecedents themselves that help in understanding the broader impact on the individual of an intervention. 
Using appropriate tools for the evaluation of behaviour: theory, research design and methods

Following on from the need to strengthen the focus of the evaluation is a need for adequate tools. Theory on behaviour and/or behavioural change serves to assist the understanding of how the choice of intervention is expected to activate the psychological process of behavioural change in relation to the target behaviour and its antecedents. This then enables an evaluation of whether the intervention seems appropriate for the target. The theoretical approach also guides the research design, the operationalisation of behaviour, and the methods employed to capture behaviour and behavioural change (e.g. Gifford 2016; Sovacool et al. 2018).

The environmental psychology literature proposes frameworks for systematically encouraging proenvironmental behaviour of individuals (e.g. Geller 2002; Guo et al. 2018; Steg and Vlek 2009). Steg and Vlek (2009) outline four fundamental steps in this process: (1) identification of which behaviour should be changed, (2) definition of which factors determine the behaviour, (3) choice of interventions and (4) evaluation of effects of the intervention on behaviour.

Several theories of behaviour have been employed to improve the understanding of psychological antecedents. These include affective factors and social costs and benefits of pro-environmental behaviour in general, as well as energy use behaviour, including the model of Psycho-Social Determinants of Pro-environmental Behaviour (Hines et al. 1986/1987), Theory of Reasoned Action (Ajzen \& Fishbein 1980), Theory of Planned Behaviour (Ajzen 1991), Norm-Activation-Model (Schwarz 1977), Value-Belief-Norm Theory (Stern 2000), Goal-framing Theory (Lindenberg and Steg 2007), Comprehensive Action Determination Model (Klöckner and Blöbaum 2010), Place Attachment, and Affordance Theory (Lenoir-Improta et al. 2017). See Guo et al. (2018) for an extensive review.

The environmental psychology approach offers theories that can be used to examine the alignment between the target group, behaviour, antecedents and intervention under study. Theory can be used to specify questions that consider what behavioural antecedents, behaviour and behavioural change are the subjects/not the subject in an evaluation. Theory should be considered as a guide to the identification of relevant psychological constructs to consider in the evaluation. The use of theory may help to identify relevant concepts, identify which concepts may have been neglected and pinpoint gaps that could be filled with new additional concepts. In environmental psychology, the design of evaluations can be chosen for the nuanced understanding of behaviour in, for example, qualitative case studies as well as in experimental studies quantitatively examining a single parameter of behaviour. More commonly, the two can be combined in a mixed-method approach.

Questions identified from the environmental psychology approach

The environmental psychology approach can be translated into specific questions regarding the focus chosen and the tools used in evaluations of energy efficiency behaviour. These questions are outlined in Table 1 can be applied to assess to what extent environmental psychology is captured, or could further complement and support, current evaluation practice. Such an assessment, covering of energy efficiency behaviour in buildings in the Nordic countries, is presented in the following sections. In addition to the questions, the alignment of the chosen focus and tools will be checked for (see also Johansson and Neij 2017). The alignment concerns for example if and how theory direct the focus, if and how focused concepts are operationalised in the tools employed etc. The alignment will tell how results from different studies can be understood, compared and potentially integrated.

\section{Material and methods}

In the following sections, we empirically test the extent to which the questions formulated in "Theory: an environmental psychology approach, key perspectives and questions" section are captured in evaluations presented in scientific peer-reviewed papers on energy efficiency behaviour in the built environment. The analysis covers papers across different disciplinary approaches in the Nordic countries (Denmark, Finland, Iceland, Norway and Sweden) and includes evaluations performed by researchers representing a variety of disciplines.

The search for relevant peer-reviewed papers was performed as follows: (i) a systematic search in electronic databases, followed by (ii) a manual search on personal pages of authors who recurred more often in the systematic search and (iii) a search in the reference list of the papers retrieved during the electronic search. 
The systematic electronic search was extended to all subject areas (see Table 2), since studies were expected to be in different disciplines.

The Scopus and Web of Science databases were selected, as they have proven reliable for such crossdisciplinary searches (Harzing and Alakangas 2016). The search was limited to papers written in English and published 1997-2018. The final search was performed in November 2018, so some very recent papers, e.g. in online first versions, may have been overlooked because they were not yet indexed by the databases (Franceschini et al. 2016).

The search focused on papers including all of the following five overarching criteria:

- Space typology, i.e. the investigated space should be a building

- Behaviour, i.e. the study should state that it investigates behaviour

- Energy, i.e. the study should clearly investigate the energy use

- Location, i.e. the study should be carried out in a Nordic country

- The research design used in the study should be based on empirical observations and include variation in the space typology/thematic area (either in an intervention or cross-sectional comparison).

A number of keywords were chosen for each criterion. The five overarching criteria and the keywords within a certain criterion were connected with the Boolean operators 'AND' and 'OR' respectively. This means that each search result should have included at least one of the keywords of each the five criteria. This resulted in relatively specific search strings with an associated number of hits, which could then be manually inspected.

The first set of keywords was decided through individual assumptions, and the search was performed on Scopus only. The search resulted in 46 hits, seven of which met the inclusion criteria. The keywords in these papers, as well as the introduction and literature review in each paper, were closely examined. This highlighted a number of synonyms that were incorporated when the search was repeated. For example, for the criterion 'research design/thematic area', Nilsson et al. (2018b) also described feedback systems as 'home energy management systems', 'energy display', or 'in-home display'. The same principle was adopted for the other criteria, e.g. the space typology included 'house', 'household', 'dwelling', 'home', 'building service', ... instead of just 'building' as in Table 2. This process was repeated until saturation was reached, i.e. searches with new keywords did not produce any new results.

The screening process for inclusion in the analysis included reading the title and the abstracts. If the abstract did not clarify the methodology, then the paper itself was analysed. Studies that did not exclusively focus upon buildings, e.g. if the focus was on more general environmental concerns and pro-environmental behaviour, and papers primarily aiming to describe antecedents of energy efficiency behaviour in buildings without presenting an introduction of new technology, comparison of buildings or other building-related environmental change, were excluded. To enable comparisons and

Table 2 Criteria and keywords used for the search in step 1

\begin{tabular}{|c|c|c|c|c|c|}
\hline & \multicolumn{5}{|c|}{ Boolean operator "AND" $\rightarrow$} \\
\hline & Space typology & Behaviour & Energy & Location & $\begin{array}{l}\text { Research design/adopted } \\
\text { strategy }\end{array}$ \\
\hline \multirow[t]{10}{*}{ Boolean operator "OR" } & Building & Behaviour & Energy & Sweden & Empirical \\
\hline & & Habits & & Denmark & Field \\
\hline & & & & Norway & Observation \\
\hline & & & & Finland & Observed \\
\hline & & & & Iceland & Experiment \\
\hline & & & & Nordic countries & Controlled \\
\hline & & & & & Case study \\
\hline & & & & & Theory \\
\hline & & & & & Interview \\
\hline & & & & & Questionnaire \\
\hline
\end{tabular}


contrasts between studies, the two major groups of intervention types pinpointing two different underlying psychological processes for behavioural change were chosen for the analyses: information-feedback approaches and building design approaches.

Information-feedback approaches draw on the idea that if people are more aware and knowledgeable about the relevant behaviour - in this case energy efficiencyand how to perform such behaviour, they will make adjustments (e.g. theory of environmental education, Hines et al. 1986/87). Information is the most common strategy used to promote energy efficiency behaviour, and this can be conveyed in several ways. Tailored information is highly personalised and specific, based on the idea that information relevant for the individual is most likely to have an effect. Tailored information on, for example, energy use is often combined with feedback from smart meters. These theories are based on the idea that the individual behaviour can be changed if an association can be made between a behaviour and a certain outcome. Building design approaches are based on the idea that the environment directly communicates with the intended user and that the physical environment can therefore support or hinder people in the performance of certain behaviour as, for example described in affordance theory (Gibson 1979).

The scope represents the diversity of disciplines used for the study of energy efficiency behaviour in the Nordic countries, and thereby also the theoretical and methodological diversity. A total of 40 studies published between 2007 and 2018 are included in the analysis. With a few exceptions, the papers are, published in journals with a focus on energy. The studies are listed in Appendix Table 3.

\section{Results - empirical test of identified questions}

The literature search resulted in a broad spectrum of articles based on a variety of disciplinary approaches. In all, the information-feedback approach involves 22 studies. In this group, there is a dominance of studies from technology and sociology, including science-technology-society (STS) studies, but the group features a larger variation in disciplinary approaches, including geography, psychology, economics and environmental studies. The building design approach, including 18 studies, is mainly found in technology and sociological and STS studies. Additional disciplines in this group are psychology, environmental medicine and architecture (Fig. 1).

The evaluation approaches applied in the articles differ with regard to the identification, definition and assessment of behaviour, and there is a difference in the outcomes considered when using different disciplinary approaches. The majority of articles on behaviour are studies with a technological approach, which often provide measurements of energy use and information on changes in actual energy use patterns (Appendix Table 3). While these studies advance measurements of energy use, as also noted internationally, the results say little about how certain

$50 \%$

\section{BUILDING DESIGN INFORMATION FEEDBACK}

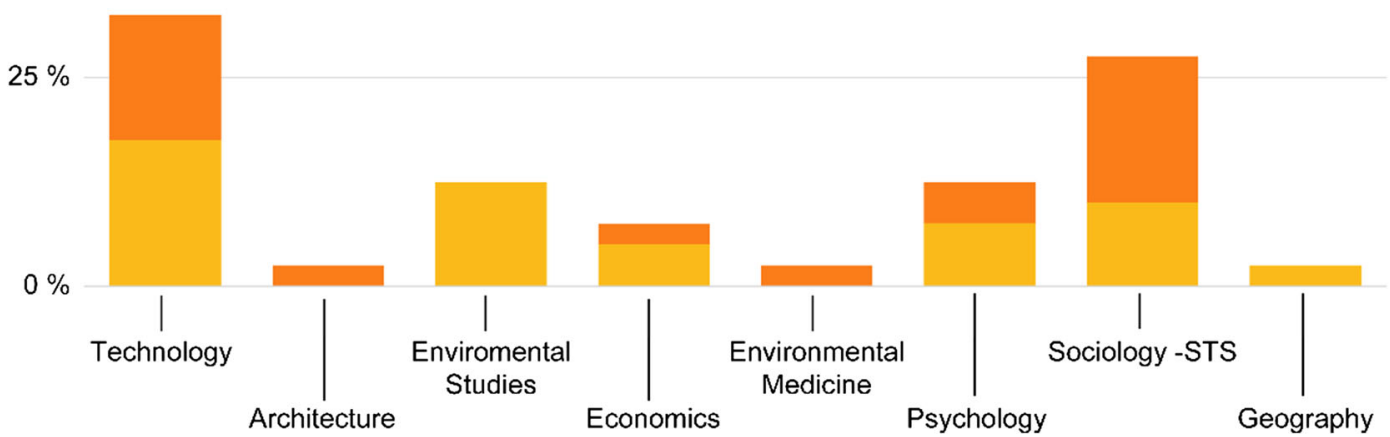

Fig. 1 Disciplines represented in the analyses of the two groups of interventions - information feedback and building design. Percentage of the total of 40 studies. The papers are distributed as follows: 26 Swedish papers (of which 10 in technology, 6 in psychology, 5 in sociology-STS, 3 in environmental studies, 2 in economics and 1 each in architecture, environmental medicine and geography); 10 Danish papers (of which 5 in sociology-STS, 3 in technology and 2 in economics); 3 Norwegian papers (of which 2 in sociology-STS and 1 in environmental studies) and 1 Finnish paper in environmental studies 
behaviour comes about and why or why not the behaviour would change in response to certain interventions. Several evaluations are based on sociology, including science and technology-studies. These evaluations use well-established solid theoretical frameworks and provide nuanced social contextual understanding of energy efficiency and the role of people's daily practices. Whereas the current evaluation practice provides a rich palette of evaluations within different disciplines, we raise the question, in the analysis below, of the potential contribution of environmental psychology in strengthening a cross disciplinary evaluation approach using the structure and questions outlined in Table 1. The results are presented in detail in the text below, while Fig. 2 illustrates key aspects of the papers in relation to environmental psychology, divided into building design interventions and information-feedback interventions.

Focus: choice of intervention and psychological process of behavioural change

The reason for choosing a specific intervention and an idea of how the intervention would activate underlying psychological processes to initiate behavioural change is often lacking. This is particularly the case in the studies of building design interventions (see Fig. 2). Notably, Glad (2012) discusses the lack of motivation for behavioural change in a study on housing renovation. Hagbert and Femenías (2016) refer to the idea of the sustainable home and argue that design per se can guide certain behaviour. Vlasova and Gram-Hanssen (2014) argue that the design of the physical environment opens up for a change of practice, and Maleetipwan-Mattsson et al. $(2016,2017)$ more specifically stress the perceived affordance of building objects to trigger energy-efficiency behaviour. In a longitudinal study, Righer Hansen (2018) focuses upon the interaction between the built environment and childhood experiences and early adult habits as factors triggering energy efficiency behaviour. In studies on information-feedback, $54 \%$ of the studies provide arguments for why or how the intervention is intended to activate psychological processes of behavioural change (Fig. 2). However, most of the arguments are limited to showing that information-feedback has been efficient in previous research, rather than providing an understanding of how the intervention suits the investigated target group and context.

\section{FOCUS}

TOOLS

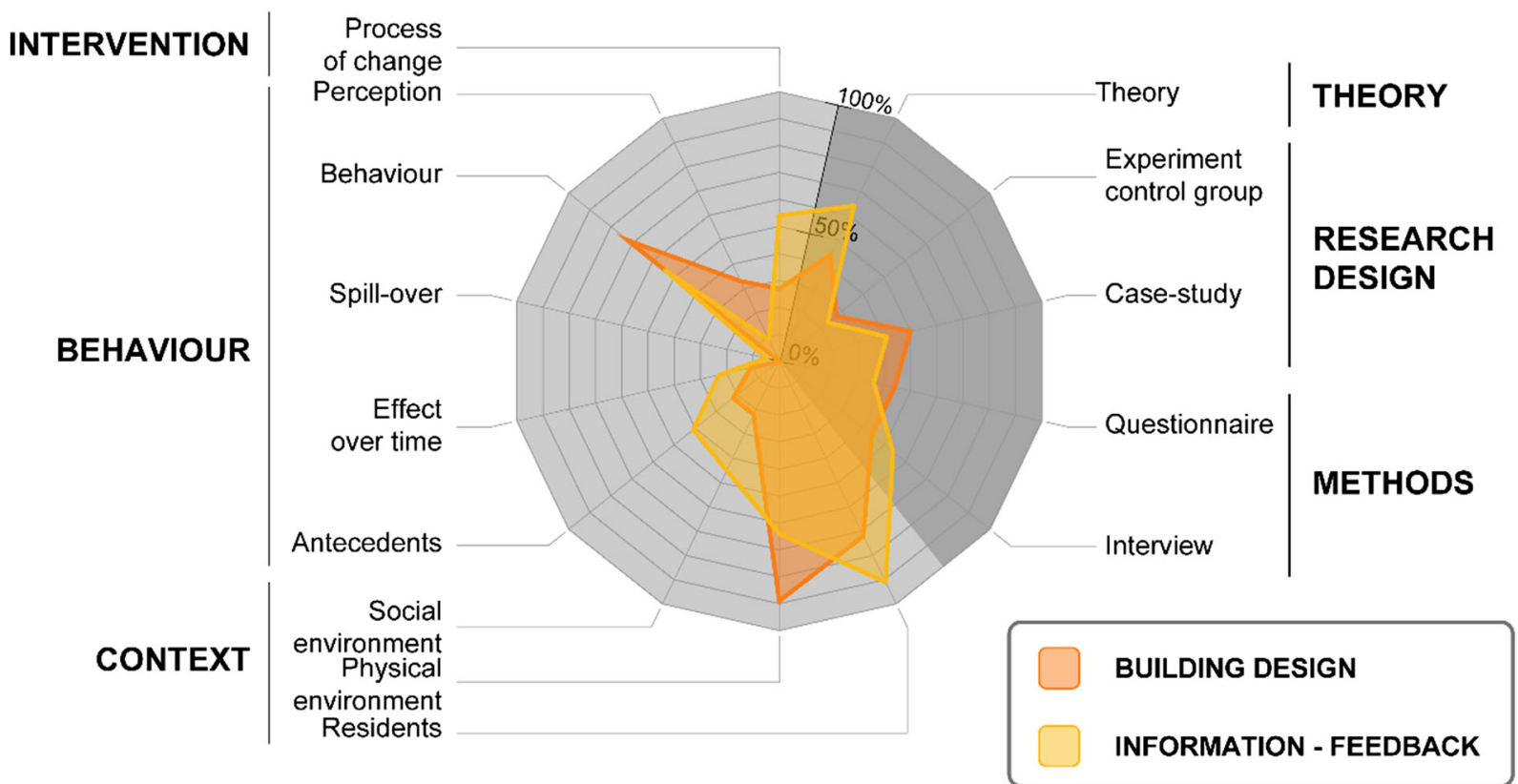

Fig. 2 Key aspects in evaluating energy efficiency behaviour, divided into building design interventions and information-feedback interventions 
Studies based on sociology and STS emphasise that information must correspond to people's daily life (Isaksson and Ellegård 2015; Skjølsvold and Ryghaug 2015; Skjølsvold et al. 2017), and draw attention to the role of intermediaries, i.e. someone is needed who can translate, communicate and tailor the information to fit people's everyday life and social practice to make change happen (Palm 2010; Salo et al. 2016). Studies based on economics and psychology, and in some cases environmental studies, refer to psychological literature on the influence of feedback on attention, motivation and learning processes (Grønhøj and Thøgersen 2011) and emphasise that information feedback may strengthen empowerment and perceived self-efficacy, and that rewards reinforce learning (Nilsson et al. 2014). Activation of norms and ascription of responsibility are stressed as elements of the psychological processes of behavioural change, showing that social influences from real people contribute to energy efficiency behaviour (Bergquist and Nilsson 2016; Ek and Söderholm 2010; Nilsson et al. 2015; Nilsson et al. 2018a), and one study refers to learning theory (Gustafsson et al. 2009).

Across the intervention types analysed, the psychological process expected to activate behavioural change is often implicitly described. The fit between intervention and current behaviour and its drivers in the target group, including their social and environmental context, is not developed further. Especially in the field of building design, a more thorough understanding of how the design is expected to support behavioural change would allow for a better fit between intervention and current behaviour.

Focus: description of target behaviour

In most studies, the target behaviour is described either as general energy use or one specific behaviour. Energy efficiency behaviour is defined, operationalised and measured in many ways, most commonly as energy consumption per household (Karlsson and Moshfegh 2007; Nilsson et al. 2017, 2018a, 2018b; Palm 2010; Vassileva et al. 2013), office unit (Nilsson et al. 2015) or classroom (Heebøll et al. 2018). Some studies identify electricity consumption per person per square metre (Vassileva et al. 2012a) or per appliance (Falabretti et al. 2018). Other studies specifically address one energy efficiency behaviour, such as lighting use behaviour (Bergquist and Nilsson 2016; Maleetipwan-
Mattsson et al. 2016, 2017) or use of heating and hot water (Glad 2012; Righer Hansen et al. 2018).

Grønhøj and Thøgersen (2011) differentiate between curtailment and investment behaviour. Other studies use triangulation to obtain a holistic picture of energy efficiency behaviour. Nilsson et al. (2015), for example, combine measurements of electricity, observation of traces of behaviour and self-reports. Nilsson et al. (2018a, 2018b) combine measurements of electricity with interviews about energy efficiency behaviour. Vassileva et al. (2013) combine electricity use with self-reporting of the frequency of use of domestic appliances. A couple of studies address a behavioural intention by asking about the willingness to perform a certain behaviour, such as willingness to install individual metering and costs (Ek and Söderholm 2010; Siggelsten and Olander 2013). Other studies discuss perception expressed as satisfaction rather than behaviour (Brunsgaard et al. 2012; Engvall et al. 2005; Heebøll et al. 2018; Karlsson and Moshfegh 2007). A couple of studies address several different household behaviours (Ek and Söderholm 2010; Zalejska-Jonsson 2012) or the broader concept of sustainable behaviour (Hagbert and Femenías 2016; Salo et al. 2016).

Antecedents of the studied behaviour are rarely addressed (see Fig. 2). Antecedents are considered regardless of the disciplinary approach, but studies based on theoretical frameworks on human behaviour (see above) tend to include antecedents of psychological character to a greater extent, whereas other studies focus upon instrumental factors that may serve to motivate behaviour. Nevertheless, these factors are neglected in the analysis of the outcome of the intervention. Commonly investigated antecedents are socioeconomic conditions and previous experiences (Ek and Söderholm 2010; Westskog et al. 2015; Righer Hansen 2018), awareness and knowledge (Gram-Hanssen et al. 2007; Palm 2010; Vassileva et al. 2012a), attitudes including environmental concern (Ek and Söderholm 2010; Nilsson et al. 2015) and norms (Ek and Söderholm 2010; Isaksson and Ellegård 2015; Maleetipwan-Mattsson et al. 2016, 2017; Nilsson et al. 2015; Nilsson et al. 2018a).

The perceived control of performing a behaviour is addressed in a few studies as perceived barriers, and in relation to operation and management of technologies (Isaksson and Ellegård 2015; Maleetipwan-Mattsson et al. 2016; Nilsson et al. 2014; Nilsson et al. 2018a). Antecedents reflecting social networks and social identities are investigated in a couple of studies (Gram- 
Hanssen et al. 2007; Nilsson et al. 2015). Rebound effects are considered in just one study, by Isaksson and Ellegård (2015), who discuss the effects of investment in renewable heating systems where the more energy efficient system results in people allowing themselves a higher temperature. The persistence of behaviour over time is studied by Engvall et al. (2005), following up the effect of reduced ventilation flow on energy use after 1 year. More recently, Nilsson et al. (2017, 2018a, 2018b) monitor demand flexibility and self-reported energy use over a year. Righer-Hansen (2018) has a unique approach, following residents' energy use over their life course.

The review reveals a large variation in definition and operationalisation of energy efficiency behaviour, largely without specifications of type and stage of the behaviour, for example if it is habitual. This limits the possibilities to make comparisons both within and between interventions. Antecedents are reflected upon, but the choice of antecedents differs greatly between disciplinary approaches, both for environmental design interventions and information-feedback interventions. The studies are also limited from an evaluation perspective in that they mostly disregard any spill-over effects or follow-up over time.

Focus: target group, physical and social context

All studies describe the target group (see Fig. 2). The most researched groups are residents focusing on households in apartments and single-family houses, and subgroups formed by these parameters. One study focuses on the board members of housing cooperatives (Siggelsten \& Olander), one study also includes energy consultancies (Palm 2010), one focuses on office workers (Nilsson et al. 2014), one on pupils and staff in a primary school (Heebøll et al. 2018) and another on university students and staff (Bergquist and Nilsson 2016). In all studies, the target group for the intervention matches the choice of sample. Gender, age and income levels are commonly reported, but other individual or social characteristics given above are not reported. A strength of the empirical studies is that they are largely carried out among the actual user groups in real settings.

The physical setting is mostly described in detail in studies on building design (see Fig. 2) including characteristics of the building, descriptions of construction, materials and technologies present, (Karlsson and Moshfegh 2007; Glad 2012; Maleetipwan-Mattsson et al. 2016, 2017; Palm and Reindl 2016; Skjølsvold et al. 2017; Vlasova and Gram-Hanssen 2014; ZalejskaJonsson 2012), but also heating and indoor temperature, humidity, airflow and $\mathrm{CO}_{2}$ concentration (e.g. Andersen et al. 2016; Madsen and Gram-Hanssen 2017; Righer Hansen et al. 2018). In studies on information-feedback, the physical setting is commonly limited to a reference to private home, house or apartment, and it is rather the feedback system, such as the smart meter introduced, that is described in detail. This distinction is logical, since it is the building design that constitutes the intervention in the first case and frequently the device in the second case.

The social settings are considered in 35\% of the studies (see Fig. 2). The descriptions vary between the studies, from a large scale such as the sociodemographics of the neighbourhood or residential area investigated (Vassileva et al. 2012b, 2013) to the household's interaction with energy advisers and other energy experts (Palm 2010; Salo et al. 2016; Vlasova and Gram-Hanssen 2014), or managers, architects and building/construction (Glad 2012; Hagbert and Femenías 2016; Palm and Reindl 2016). Where the focus is on information-feedback interventions, the interaction with the close social setting, e.g. family members is discussed (Grønhøj and Thøgersen 2011; Westskog et al. 2015). The descriptions of the social settings are more varied than descriptions of the physical setting, probably due to the disciplinary approach. The descriptions are particularly elaborated in studies based on social-practice theory.

Tools: theory

In the evaluation of interventions theory, research design and methods are tools used to systematically analyse real-world problems (Robson 2011). There is a heterogeneity in how theory is used as a tool to focus the study and guide the choice of concepts for describing the target behaviour, behavioural change and its context. In studies grounded in sociology and STSstudies, social practice theory dominates (Glad 2012; Palm and Reindl 2016; Skjølsvold et al. 2017; Vlasova and Gram-Hanssen 2014). Isaksson and Ellegård (2015) employ a time geographical approach. The economic approach combines theory on, for example bounded rationality with psychological concepts including norm theory (Ek and Söderholm 2010; Grønhøj and Thøgersen 2011). The studies based on psychological theory include learning theory, theory on group identity 
and goal framing (Bergquist and Nilsson 2016; Nilsson et al. 2014, 2015), theory of planned behaviour and affordance theory (Maleetipwan-Mattsson et al. 2016, 2017). These theories are also occasionally used in studies departing from environmental sciences (Nilsson et al. 2018a). Westskog et al. (2015) argue for a combination of social practice theory and behaviouristic models. The application of theory relating to human behaviour or behavioural change is rarely employed in studies departing from technological approaches, regardless of whether building design or information-feedback is the focus. There seems to be scope for improvement, especially when the aim is to gain in-depth knowledge of how the intervention introduced should motivate behavioural change, and to align interventions with current behaviour and antecedents.

Tools: research design and methods

To some extent, the choice of theory guides which research design and methods are feasible. Among the analysed studies, the case study combined with a qualitative analysis of interviews is by far the most common set-up (Glad 2012; Hagbert and Femenías 2016; Isaksson and Ellegård 2015; Palm 2010; Palm and Reindl 2016; Skjølsvold et al. 2017; Vlasova and Gram-Hanssen 2014; Westskog et al. 2015). Some of these studies include additional methods, such as observations and on-site visits (Palm and Reindl 2016). One study uses an action research approach (Salo et al. 2016). Cross-sectional studies based on survey data and/or energy use behaviour between sub-samples are another common research design (Ek and Söderholm 2010; Gram-Hanssen et al. 2007; Liu et al. 2015; Vassileva et al. 2012a, 2012b, 2013).

A somewhat stronger research design is the matchedcase design employed by Zalejska-Jonsson (2012). The mixed-method approach also has the potential to provide more comprehensive data. Interviews, surveys and energy use measures are sometimes combined (Brunsgaard et al. 2012; Grønhøj and Thøgersen 2011; Siggelsten and Olander 2013). A few studies employ experimental research designs of varying strengths (Cook and Campbell 1979; Sovacool et al. 2018). In the post-test only design, validity is for example threatened (Rohdin et al. 2014). The experimental set-up with randomisation to experimental and control group plus follow-up interviews used by Nilsson et al. $(2014,2015)$ is a stronger design in this respect. Other strong designs are reported by Bergquist and Nilsson (2016) who used a quasi-experiment in the field combined with an online experiment, and studies employing longitudinal approaches (Engvall et al. 2005; Nilsson et al. 2017, 2018a, 2018b; Righer-Hansen et al. 2018). However, all studies are field studies, so practical matters and research ethics may have limited the use of experimental designs. A wider use of control groups or reference groups is called for, especially considering that the different empirical studies are hard to compare.

\section{Alignment}

The alignment is strongly influenced by the disciplinary approach, as previously identified by for example Schweber and Leiringer (2012). In the Nordic research on energy efficiency behaviour in buildings, three major strands of alignment can be identified (Fig. 3, categorisation of papers listed in Appendix Table 3). The first, a technological approach (13 papers), is characterised by a focus on energy per se, with careful measurement and analysis including, for example log data of energy use down to room, apartment or household level (e.g. Heebøll et al. 2018; Vassileva et al. 2013). The most common focus is on residents/households, and if additional data is collected, information is gathered either by questionnaires or interviews in a case study or a cross-sectional study. Generally, the theoretical foundation is vague with regard to the choice of intervention and the description of target behaviour. Antecedents are limited to sociodemographics, and there are rarely detailed descriptions of the physical and social settings.

The sociological-STS studies approach (13 papers, including the one in geography) is characterised by broadening the understanding of the context, especially the social context of energy efficiency behaviour. The predominant theory is social practice theory, in some studies combined with additional theoretical frameworks (e.g. Glad 2012; Palm and Reindl 2016; Skjølsvold and Ryghaug 2015). This approach focuses on the case study methodology; information is obtained from interviews, sometimes together with other methods such as observations, aiming at a rich and nuanced understanding of household energy efficiency behaviour.

The psychological-economic approach (9 papers, including the one in environmental medicine), applies theory to motivate the expected change in response to 
the intervention (e.g. Ek and Söderholm 2010; Maleetipwan-Mattsson et al. 2017; Nilsson et al. 2015) and presents an extensive set of possible antecedents such social norms and perceived affordances of a device. These studies make use of cross-sectional, quasiexperimental or experimental research designs. Data is primarily collected by self-reported energy use, obtained from questionnaires. These studies vary in the richness of the description of physical and social setting.

Five papers departing from a multidisciplinary environmental science perspective form a fourth group, but this group is possibly primarily shaped by three of the papers being carried out by the same research group, so these were not analysed in detail (Nilsson et al. 2017, 2018a, 2018b).

The alignments identified come through as result of disciplinary traditions with different expertise and practices in collecting empirical data in field rather than an outcome of carefully planned strategies to evaluate the effect of information/feedback or building design in a co-ordinated way. A specific issue is the definition of target behaviour and its operationalisation in the empirical work, presenting large variation between studies including self-reported behaviour in interviews and questionnaires as well as measures of energy use. Here, promising attempts of methodological triangulation can be seen across the approaches (e.g. Nilsson et al. 2014; Nilsson et al. 2018a,b; Palm et al. 2018; Vassileva et al. 2013), but further work would be needed to build a shared knowledge base.

\section{Discussion}

Behavioural change is seen as one of the main paths towards energy efficiency in buildings (Lucon et al. 2014), but researchers consistently report that we are far from seeing the full potential of the social and behavioural domains in energy efficiency behaviour (Bögel and Upham 2018; Lenoir-Improta et al. 2017; Moezzi and Janda 2014; Schweber and Leiringer 2012; Sovacool 2014; Stern 2017). A transition to energy efficiency by capturing and focusing on human behaviour is needed. This requires thorough evaluation of human behavioural responses interventions aiming at energy efficiency. This study sheds light on the need for detailed evaluation of energy efficiency behaviour in the Nordic countries. Specifically, the analysis looked into the potential contribution of environmental psychology in evaluating interventions for energy efficiency in particular as a complement to studies in technology and sociology - STS.

The questions identified in "Theory: an environmental psychology approach, key perspectives and questions" section, and used in our assessment of the current evaluation practice, addressed the focus of the evaluation and showed the necessity to be holistic when examining real-world problems, considering the target group including their physical and social context. At the same time, it is necessary to go into depth and detail to understand how of the intervention introduced may activate the psychological process of behavioural change, and the effects on the target behaviour and its antecedents, other behaviour (spillover and rebound) and the effects over time. The focus should be supported by adequate tools in terms of theory of human behaviour and behavioural change, as well as research designs and methods that can capture energy efficiency behaviour. The choice of focus and tools should be aligned.

The disciplinary approach used to study the intervention and the consequent alignment between the focus of the evaluation and tools employed in the evaluation shows greater variations than seen between the two groups of interventions (Fig. 3). This suggests that, currently, evaluations of energy efficiency behaviour depend on who designs the evaluation. Although a broad range of disciplinary approaches is employed, the analysis confirms that current research leans towards existing well-recognised technological approaches (Johansson and Neij 2017). The technological approach has primarily been complemented and contrasted with studies based in sociology and STS elaborating on the role of people's daily practices. These evaluations often direct attention to the role of the social context using the household as the unit of analysis and address the household's interaction with energy advisers and other energy experts or managers, architects and construction companies (Fig. 2). The present study proposes that more efforts are needed to coordinate evaluations departing from different disciplinary approaches as the identified alignments have different focus and strengths in their use of theoretical and methodological tools. Here, some attempts have been made by researchers with a basis in environmental sciences (e.g. Nilsson et al. 2018b), but there is no example of integration of the three identified alignments. This is a missed opportunity of holistic evaluation capturing interactions between individual and social processes in energy efficiency behaviour and measured energy use. It could be argued that this finding 
FOCUS

TOOLS

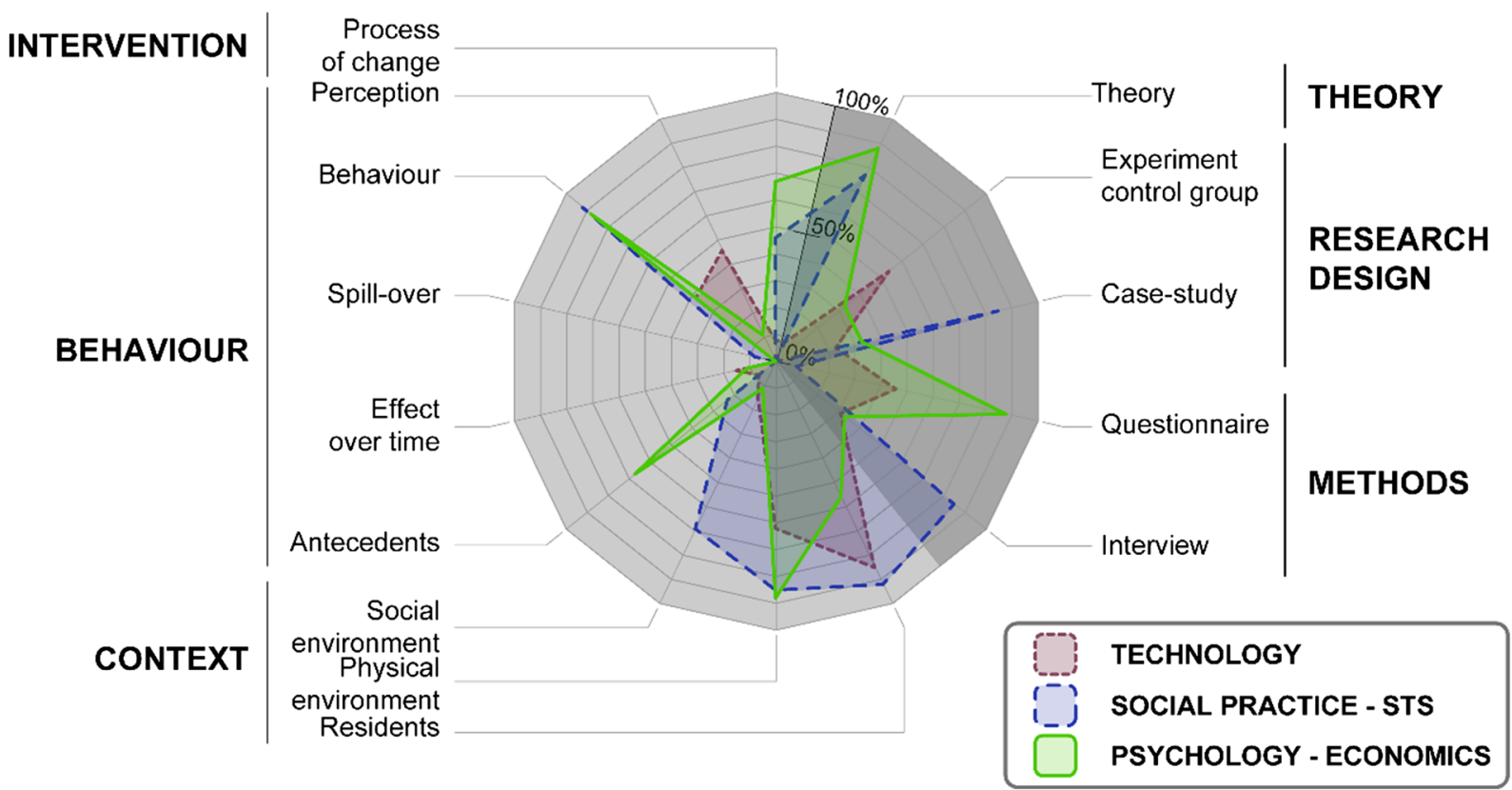

Fig. 3 Key aspects in evaluating energy efficiency behaviour divided according to disciplinary approach to illustrate alignment (Technology, Sociology-Science-Technology Studies, Psychology-Economics)

could be attributed to the choice of reviewing scientific papers rather than commissioned evaluations. Previous research shows however that at least in Swedish policy programme evaluations of energy efficiency in buildings, behaviour is rarely considered at all (Sandin et al. 2019).

While recognising that each discipline can make a unique contribution and that the psychological perspective is less common in the Nordic research on energy efficiency behaviour than in other parts of Europe, there is a potential benefit from adding environmental psychology perspectives in future evaluations. The environmental psychology perspective allows analysis of psychological antecedents-behaviour-intervention and behavioural change are linked, and analysis of a broader context of spillover, rebound, a long-time perspective and the parallel analysis of physical and social setting. In the international literature, the sociological and the psychological approaches have sometimes been conflicted in their analysis of energy efficiency behaviour. This analysis, revealing different alignments between these two disciplinary approaches, instead shows an urgent need to systematically combine them and to develop shared theoretical frameworks linking the collective with the individual. In parallel using qualitative case studies and quantitative survey data, and at the same time integrating technically sound energy measures. Openings may be found beyond the singular use of theories strongly focusing on the individual, such as the theory of planned behaviour and norm activation theory, by enabling integration of less individualistic theories used in environmental psychology, such as place attachment and social representation (Bögel and Upham 2018; Lenoir-Improta et al. 2017).

The studies included in the analysis reflected the disciplinary diversity of studies on energy efficiency behaviour in the Nordic countries, but were limited to two groups of common interventions - informationfeedback and building design. The analysis of evaluations of these two groups of interventions yielded quite similar results. This suggests that in evaluations of energy efficiency behaviour, interventions are not specifically designed in relation to the target behaviour per se, the intervention introduced or the physical and social setting of the intervention. The lack of specificity may be an advantage if the aim is to build a general knowledge base. However, that would require a shared understanding of focus currently not seen in the included evaluations. The lack of specificity may rather miss 
out on an in-depth understanding of what factors support or hinder the behavioural change.

In future evaluations, it would be desirable to clearly state how the intervention was intended to activate the psychological process of behavioural change; so far, this has been rarely done, especially in interventions on building design. The limited use of theory on human behaviour or practice across evaluations of the two groups of interventions shows a clear potential to strengthen current evaluations. Especially considering target behaviour being split between evaluation of perception of the intervention and the behavioural outcome of the intervention. Regardless of the exactness of applied energy measures, it would be worthwhile to evaluate spill-over effects (Isaksson and Ellegård 2015), and follow-up long-term effects of interventions on behaviour to evaluate the actual energy efficiency of an intervention.

The two groups of interventions showed a common focus on residents, but a lack of behavioural antecedents beyond their sociodemographics. The literature on proenvironmental behaviour suggests that it may be relevant to consider personality, values, attitudes and norms as well as how people relate to the place and other people there (Gifford and Nilsson 2014; Steg et al. 2015). More effort could also be made to define how easy or difficult the behaviour is changed i.e. the plasticity of the behaviour (Dietz et al. 2009) or the current stage of the behaviour among participants to adapt interventions to match the users' need of support in the process of changing their behaviour (Geller 2002). A more detailed understanding of how individual and social factors play into the desired energy efficiency behaviour, and of how the intervention introduced interacts with psychological and social processes would build capacity to design more powerful interventions over time (Stern 2014). The studies on building design interventions were, in general, strong in the contextual description of the physical environment, while the information-feedback interventions address the social context (Fig. 2). Here seems to be an opportunity for learning between evaluations of intervention types.

The analysis was based on systematic searches, applying an extensive search string and limiting the searches to two groups of interventions. The research field was shown to be highly diverse in scope and terminology, so some evaluations may have been missed. However, considering the large number of abstracts covered in the searches, the major conclusions drawn could be expected to be valid. It should also be noted that case studies only describing one environmental condition without making comparisons across target groups, environmental and/or social contexts or over time were not considered as evaluations, and the analysis excluded studies based on modelling and assumptions rather than analysis of energy efficiency behaviour. The latter group of studies in particular is likely to show a different alignment to those identified.

The analysis is limited in geographical scope, thereby limiting the generalisability of the results to the Nordic countries. Few studies were found that compared interventions on energy efficiency behaviour between countries, with one exception (Gram-Hanssen et al. 2007). Considering the extensive research on energy efficiency behaviour in Europe and the USA, cross-cultural evaluations of interventions would enable a broader understanding of energy efficiency behaviour in the built environment.

\section{Conclusions}

Evaluation of transformative change in energy efficient behaviour must be based on an understanding of behaviour at both individual and collective level. At the individual level, environmental psychology can offer lenses that may complement traditional current evaluations in the Nordic countries, and can provide a framework for posing critical questions when designing evaluations and analysing the outcomes. Several of these questions address features proposed as being central in transformative change, and adding them in current evaluation frameworks would provide a stronger cross disciplinary understanding of behavioural change (e.g. Neij et al. 2021). Our analysis of Nordic interventions indicates the challenges ahead in building a solid platform for learning, but also shows the breadth and variety present in the study of energy efficient behaviour. The multifaceted perspectives require efforts to combine approaches, but are also very promising for obtaining holistic evaluations of transitory changes in energy efficiency behaviour. These can then be compared across interventions and discussed from different disciplinary approaches.

Funding Open access funding provided by Lund University. The research was funded by the Swedish Energy Agency project no P39938

\section{Declarations}

Conflict of interest The authors declare no competing interests. 


\section{Appendix}

Table 3 Overview of papers included in the review. Full references are available in the list of references

\begin{tabular}{|c|c|c|c|c|c|c|}
\hline No & Author & Year & Journal & Country & Intervention type & $\begin{array}{l}\text { Disciplinary } \\
\text { approach }\end{array}$ \\
\hline 1. & Engvall et al. & 2005 & Indoor Air & Sweden & Building design & $\begin{array}{l}\text { Environmental } \\
\text { medicine }\end{array}$ \\
\hline 2. & Gram-Hansen et al. & 2007 & Energy Policy & Denmark & Information & Sociology-STS \\
\hline 3. & Karlsson \& Mosfegh & 2007 & Renewable Energy & Sweden & Building design & Technology \\
\hline 4. & Gustafsson et al. & 2009 & Computers in Entertainment & Sweden & Information-feedback & Technology \\
\hline 5. & Ek \& Söderholm & 2010 & Energy Policy & Sweden & Information-feedback & Economy \\
\hline 6. & Palm & 2010 & Energy Policy & Sweden & Information-feedback & Sociology-STS \\
\hline 7. & $\begin{array}{l}\text { Grønhøj \& } \\
\text { Thørgensen }\end{array}$ & 2011 & International Journal of Consumer Studies & Denmark & Information-feedback & Economy \\
\hline 8. & Brunsgaard et al. & 2012 & Indoor and Built Environment & Denmark & Building design & Technology \\
\hline 9. & Glad & 2012 & Building Research and Information & Sweden & Building design & Sociology-STS \\
\hline 10 & Zalejska-Jonsson & 2012 & Building and Environment & Sweden & Building design & Technology \\
\hline 11. & Vassileva et al. & $2012 \mathrm{a}$ & Applied Energy & Sweden & Information-feedback & Technology \\
\hline 12. & Vassileva et al. & $2012 b$ & Applied Energy & Sweden & Information-feedback & Technology \\
\hline 13. & Siggelsten \& Olander & 2013 & Energy Policy & Sweden & Information-feedback & Technology \\
\hline 14. & Vassileva et al. & 2013 & Applied Energy & Sweden & Information-feedback & Technology \\
\hline 15. & Nilsson et al. & 2014 & Applied Energy & Sweden & Information-feedback & Psychology \\
\hline 16. & Rohdin et al. & 2014 & Building and Environment & Sweden & Building design & Technology \\
\hline 17. & $\begin{array}{l}\text { Vlasova \& } \\
\text { Gram-Hanssen }\end{array}$ & 2014 & Building Research and Information & Denmark & Building design & Sociology-STS \\
\hline 18 & Isaksson \& Ellegård & 2015 & & Sweden & Information-feedback & Geography \\
\hline 19. & Liu et al. & 2015 & Energy and Buildings & Sweden & Building design & Technology \\
\hline 20. & $\begin{array}{l}\text { Skjølsvold \& } \\
\text { Ryghaug }\end{array}$ & 2015 & Indoor and Built Environment & Norway & Information-feedback & Sociology-STS \\
\hline 21. & Nilsson et al. & 2015 & Applied Energy & Sweden & Information-feedback & Psychology \\
\hline 22. & Westskog et al. & 2015 & Sustainability & Norway & Information-feedback & $\begin{array}{l}\text { Environmental } \\
\text { studies }\end{array}$ \\
\hline 23. & Andersen et al. & 2016 & Energy and Buildings & Denmark & Information-feedback & Technology \\
\hline 24. & Bergquist \& Nilsson & 2016 & Journal of Environmental Psychology & Sweden & Information-feedback & Psychology \\
\hline 25. & Hagbert \& Femenias & 2016 & $\begin{array}{l}\text { Journal of Housing and the Built } \\
\text { Environment }\end{array}$ & Sweden & Building design & Architecture \\
\hline 26. & Mattsson et al. & 2016 & Building and Environment & Sweden & Building design & Psychology \\
\hline 27. & Palm \& Reindl & 2016 & Energy Research and Social Science & Sweden & Building design & Sociology-STS \\
\hline 28. & Salo et al. & 2016 & Journal of Cleaner Production & Finland & Information-feedback & $\begin{array}{l}\text { Environmental } \\
\text { studies }\end{array}$ \\
\hline 29. & Mattsson et al. & 2017 & $\begin{array}{l}\text { Journal of Engineering, Design and } \\
\text { Technology }\end{array}$ & Sweden & Building design & Psychology \\
\hline 30. & Nilsson et al. & 2017 & Resources, Conservation and Recycling & Sweden & Information-feedback & $\begin{array}{l}\text { Environmental } \\
\text { studies }\end{array}$ \\
\hline 31. & Skjølsvold et al. & 2017 & Energy Research \& Social Science & Norway & Information-feedback & Sociology-STS \\
\hline 32. & Baldini et al. & 2018 & Energy Policy & Denmark & Building design & Economy \\
\hline 33. & Falabretti et al. & 2018 & Journal of Energy Storage & Sweden & Information-feedback & Technology \\
\hline 34. & Heebøll et al. & 2018 & Science and Technology for the Built & Denmark & Building design & Technology \\
\hline
\end{tabular}


Table 3 (continued)

\begin{tabular}{|c|c|c|c|c|c|c|}
\hline No & Author & Year & Journal & Country & Intervention type & $\begin{array}{l}\text { Disciplinary } \\
\text { approach }\end{array}$ \\
\hline 35. & Nilsson et al. & $2018 \mathrm{a}$ & Energy Policy & Sweden & Information-feedback & $\begin{array}{l}\text { Environmental } \\
\text { studies }\end{array}$ \\
\hline 36. & Nilsson et al. & $2018 b$ & Energy and Buildings & Sweden & Information-feedback & $\begin{array}{l}\text { Environmental } \\
\text { studies }\end{array}$ \\
\hline 37. & Palm et al. & 2018 & Energy Research and Social Science & Sweden & Building design & Sociology-STS \\
\hline 38. & Righer-Hansen & 2018 & Energy Research and Social Science & Denmark & Building design & Sociology-STS \\
\hline 39. & Righer Hansen et al. & 2018 & Building Research \& Information & Denmark & Building design & Sociology-STS \\
\hline 40. & Madsen & 2018 & Energy Research and Social Science & Denmark & Building design & Sociology-STS \\
\hline
\end{tabular}

Open Access This article is licensed under a Creative Commons Attribution 4.0 International License, which permits use, sharing, adaptation, distribution and reproduction in any medium or format, as long as you give appropriate credit to the original author(s) and the source, provide a link to the Creative Commons licence, and indicate if changes were made. The images or other third party material in this article are included in the article's Creative Commons licence, unless indicated otherwise in a credit line to the material. If material is not included in the article's Creative Commons licence and your intended use is not permitted by statutory regulation or exceeds the permitted use, you will need to obtain permission directly from the copyright holder. To view a copy of this licence, visit http://creativecommons.org/licenses/by/4.0/.

\section{References}

Abrahamse, W., Steg, L., Vlek, C., \& Rothengatter, T. (2005). A review of intervention studies aimed at household energy conservation. Journal of Environmental Psychology, 25(3), 273-291. https://doi.org/10.1016/j.jenvp.2005.08.002.

Ajzen, I. (1991). The theory of planned behavior. Organizational Behavior and Human Decision Processes, 50(2), 179-211. https://doi.org/10.1016/0749-5978(91)90020-T.

Ajzen, I., \& Fishbein, M. (1980). Understanding attitudes and predicting social behavior. New Jersey: Prentice-Hall Inc.

Amel, E., Manning, C., Scott, B., \& Koger, S. (2017). Beyond the roots of human inaction: fostering collective effort toward ecosystem conservation. Science, 356(6335), 275-279. https://doi.org/10.1126/science.aal1931.

Andersen, R. K., Fabi, V., \& Corgnati, S. P. (2016). Predicted and actual indoor environmental quality: verification of occupants' behaviour models in residential buildings. Energy and Buildings, 127, 105-115. https://doi.org/10.1016/j. enbuild.2016.05.074.

Bergquist, M., \& Nilsson, A. (2016). I saw the sign: promoting energy conservation via normative prompts. Journal of Environmental Psychology, 46, 23-31. https://doi. org/10.1016/j.jenvp.2016.03.005.

Bögel, P. M., \& Upham, P. (2018). Role of psychology in sociotechnical transitions studies: Review in relation to consumption and technology acceptance. Environmental Innovation and Societal Transitions, 28, 122-136. https://doi.org/10.1016/j.eist.2018.01.002.

Brunsgaard, C., Heiselberg, P., Knudstrup, M.-A., \& Larsen, T. S. (2012). Evaluation of the indoor environment of comfort houses: qualitative and quantitative approaches. Indoor and Built Environment, 21(3), 432-451. https://doi.org/10.1177 /1420326X11431739.

Carlsson-Kanyama, A., \& Lindén, A. -L. (2007). Energy efficiency in residences-challenges for women and men in the north. Energy Policy, 35(4), 2163-2172. https://doi.org/10.1016/j. enpol.2006.06.018.

Chatterton, T., \& Wilson, C. (2013). Characterising domestic energy related behaviours. Eceee summer study proceedings, 289-300.

Cook, T. D., \& Campbell, D. T. (1979). Quasi-experimentation. Design and analysis issues for field settings. Chicago, U.S.: McNally.

Dietz, T., Stern, P. C., \& Weber, E. U. (2013). Reducing carbonbased energy consumption through changes in household behavior. Daedalus, 142(1), 78-89. https://doi.org/10.1162 /DAED_a_00186.

Dietz, T., Gardner, G. T., Gilligan, J., Stern, P. C., \& Vandenbergh, M. P. (2009). Household actions can provide a behavioral wedge to rapidly reduce US carbon emissions. Proceedings of the National Academy of Sciences of the United States of America, 106(44), 18452-18456. https://doi.org/10.1073/pnas.0908738106.

Dwyer, W. O., Leeming, F. C., Cobern, M. K., Porter, B. E., \& Jackson, J. M. (1993). Critical review of behavioral interventions to preserve the environment: research since 1980 . Environment and Behavior, 25(5), 275-321. https://doi. org/10.1177/0013916593255001.

Ek, K., \& Söderholm, P. P. (2010). The devil is in the details: household electricity saving behavior and the role of information. Energy Policy, 38(3), 1578-1587. https://doi. org/10.1016/j.enpol.2009.11.041.

Engvall, K., Wickman, P., \& Norbäck, D. (2005). Sick building syndrome and perceived indoor environment in relation to energy saving by reduced ventilation flow during heating season: a 1 year intervention study in dwellings. Indoor Air, 15(2), 120-126. https://doi.org/10.1111/j.16000668.2004.00325.x. 
Falabretti, D., Lindholm, B., Merloa, M., \& Mastrogiacomo, L. (2018). Energy storage coupling in a high efficiency household scenario: a real life experimental application. Journal of Energy Storage, 17, 496-506. https://doi.org/10.1016/j. est.2018.04.010.

Franceschini, F., Maisano, D., \& Mastrogiacomo, L. (2016). Empirical analysis and classification of database errors in Scopus and Web of Science. Journal of Informetrics, 10(4), 933-953. https://doi.org/10.1016/j.joi.2016.07.003.

Gardner, G. T., \& Stern, P. C. (1996). Environmental problems and human behaviour. Boston: Allyn \& Bacon.

GEA. (2012). Global assessment - toward a sustainable future. Cambridge University Press, Cambridge, UK and New York, NY, USA and the International Institute for Applied System Analysis, Laxenburg, Austria.

Geller, E. S. (2002). The challenge of increasing proenvironment behaviour. In R. Bechtel \& A. Churchman (Eds.), Handbook of environmental psychology. New York: Wiley.

Gibson, J. J. (1979). The ecological approach to visual perception. Boston, US.: Houghton Mifflin Harcourt.

Gifford, R. (2014). Environmental psychology (5th ed.). Colville, U.S.: Optimal Books.

Gifford, R. (Ed.). (2016). Research methods for environmental psychology. Chichester, UK: John Wiley \& Sons.

Gifford, R., \& Nilsson, A. (2014). Personal and social factors that influence pro-environmental concern and behaviour: a review. International Journal of Psychology, 49(3), 141-157. https://doi.org/10.1002/ijop.12034.

Glad, W. (2012). Housing renovation and energy systems: the need for social learning. Building Research and Information, 40(3), 274-289. https://doi.org/10.1080 /09613218.2012.690955.

Gram-Hanssen, K. (2010). Residential heat comfort practices: understanding users. Building Research and Information, 38(2), 175-186. https://doi.org/10.1080 /09613210903541527.

Gram-Hanssen, K. (2014). New needs for better understanding of household's energy consumption - behaviour, lifestyle or practices? Architectural Engineering and Design Management, 10(1-2), 91-107. https://doi.org/10.1080 $/ 17452007.2013 .837251$.

Gram-Hanssen, K., Bartiaux, F., Jensen, M. O., \& Cantaert, M. (2007). Do homeowners use energy labels? A comparison between Denmark and Belgium. Energy Policy, 35(5), 28792888. https://doi.org/10.1016/j.enpol.2006.10.017.

Grønhøj, A., \& Thøgersen, J. (2011). Feedback on household electricity consumption: learning and social influence processes. International Journal of Consumer Studies, 35(2), 138-145. https://doi.org/10.1111/j.1470-6431.2010.00967. $\mathrm{x}$.

Guo, Z., Zhou, K., Zhang, C., Lu, X., Chen, W., \& Yang, S. (2018). Residential electricity consumption behavior: Influencing factors, related theories and intervention strategies. Renewable and Sustainable Energy Reviews, 81, 399412. https://doi.org/10.1016/j.rser.2017.07.046.

Gustafsson, A., Katzeff, C., \& Bang, M. (2009). Evaluation of a pervasive game for domestic energy engagement among teenagers. Computers in Entertainment, 7(4), 1. https://doi. org/10.1145/1658866.1658873.

Hagbert, P., \& Femenías, P. (2016). Sustainable homes, or simply energy-efficient buildings? Journal of Housing and the Built
Environment, 31(1), 1-17. https://doi.org/10.1007/s10901015-9440-y.

Hargreaves, T. (2011). Practice-ing behaviour change: applying social practice theory to pro-environmental behaviour change. Journal of Consumer Culture, 11(1), 79-99. https://doi.org/10.1177/1469540510390500.

Harzing, A.-W., \& Alakangas, S. (2016). Google Scholar, Scopus and the Web of Science: a longitudinal and cross-disciplinary comparison. Scientometrics, 106(2), 787-804. https://doi. org/10.1007/s11192-015-1798-9.

Heebøll, A., Wargocki, P., \& Toftum, J. (2018). Window and door opening behavior, carbon dioxide concentration, temperature, and energy use during the heating season in classrooms with different ventilation retrofits-ASHRAE RP1624. Science and Technology for the Built Environment, 24(6), 626-637. https://doi.org/10.1080/23744731.2018.1432938.

Hiller, C. (2020). What have residents got to do with it? Variations in energy use and energy-related behaviours in single-family houses. Doctoral Dissertation: Building Physics, Lund University, Lund, Sweden. https://portal.research.lu. se/portal/sv/publications/what-have-residents-got-to-dowith-it(5f19c25d-9912-4e3d-9 ac8-638120e1c625).html

Hines, J. M., Hungerford, H. R., \& Tomera, A. N. (1986/87). Analysis and synthesis of research on responsible environmental behaviour: A meta-analysis. The Journal of Environmental Education, 18(2), 1-8.

Huijts, N. M. A., Molin, E. J. E., \& Steg, L. (2012). Psychological factors influencing sustainable energy technology acceptance: a review-based comprehensive framework. Renewable and Sustainable Energy Reviews, 16(1), 525531. https://doi.org/10.1016/j.rser.2011.08.018.

IEA, International Energy Agency. (2018). 'Energy efficiency 2018 - analysis and outlooks 2040'.

Isaksson, C., \& Ellegård, K. (2015). Anchoring energy efficiency information in households' everyday projects: peoples' understanding of renewable heating systems. Energy Efficiency, 8(2), 353-364. https://doi.org/10.1007/s12053-014-9299-x.

Johansson, M., \& Neij, L. (2017). Addressing human behaviour in assessments of energy efficiency in buildings. In ECEEE summer study proceedings, Consumption, Efficiency \& Limits. France (s. 2129-2138).

Karlsson, J. F., \& Moshfegh, B. (2007). A comprehensive investigation of a low-energy building in Sweden. Renewable Energy, 32(11), 1830-1841. https://doi.org/10.1016/j. renene.2006.10.009 https://www.ecee . org/library/conference_proceedings/eceee_Summer_ Studies/2017/.

Keller, M., Halkier, B., \& Wilska, T. (2016). Policy and governance for sustainable consumption at the crossroads of theories and concepts. Environmental Policy and Governance, 26(2), 75-88. https://doi.org/10.1002/eet.1702.

Klöckner, C. A., \& Blöbaum, A. (2010). A comprehensive action determination model: Toward a broader understanding of ecological behaviour using the example of travel mode choice. Journal of Environmental Psychology, 30(4), 574 586. https://doi.org/10.1016/j.jenvp.2010.03.001.

Küller, R. (1991). Environmental assessment from a neuropsychological perspective. In T. Gärling \& G. W. Evans (Eds.), Environment, Cognition and Action (pp. 111-147). New York, NY: Oxford Univ. Press. 
Lenoir-Improta, R., Devine-Wright, P., Pinheiro, J. Q., \& Schweizer-Ries, P. (2017). Energy issues: psychological aspects. In G. Fleury-Bahi, E. Pol, \& O. Navarro (Eds.), Handbook of Environmental Psychology and Quality of Life Research. Switzerland: Springer.

Lindén, A.-L. (2001). Allmänhetens miljöpåverkan. energi, mat, resor och socialt liv. Stockholm: Carlssons.

Lindenberg, S., \& Steg, L. (2007). Normative, gain and hedonic goal frames guiding environmental behavior. Journal of Social Issues, 63(1), 117-137. https://doi.org/10.1111 /j.1540-4560.2007.00499.x.

Liu, L., Rohdin, P., \& Moshfegh, B. (2015). Evaluating indoor environment of a retrofitted multi-family building with improved energy performance in Sweden. Energy and Buildings, 102, 32-44. https://doi.org/10.1016/j. enbuild.2015.05.021.

Lucon, O., Ürge-Vorsatz, D., Zain Ahmed, A., Akbari, H., Bertoldi, P., Cabeza, L. F., Eyre, N., Gadgil, A., Harvey, L. D. D., Jiang, Y., Liphoto, E., Mirasgedis, S., Murakami, S., Parikh, J., Pyke, C., \& Vilariño, M. V. (2014). Buildings. In O. Edenhofer, R. Pichs-Madruga, Y. Sokona, E. Farahani, S. Kadner, K. Seyboth, A. Adler, I. Baum, S. Brunner, P. Eickemeier, B. Kriemann, J. Savolainen, S. Schlömer, C. von Stechow, T. Zwickel, \& J. C. Minx (Eds.), Climate Change 2014: Mitigation of climate change. Contribution of Working Group III to the Fifth Assessment Report of the Intergovernmental Panel on Climate Change. Cambridge, United Kingdom and New York, NY, USA: Cambridge University Press.

Madsen, L. V., \& Gram-Hanssen, K. (2017). Understanding comfort and senses in social practice theory: insights from a Danish field study. Energy Research and Social Science, 29, 86-94. https://doi.org/10.1016/j.erss.2017.05.013.

Maleetipwan-Mattsson, P., Laike, T., \& Johansson, M. (2016). Factors affecting optimal lighting use in shared hospital environments: A case-study. Building and Environment, 96, 260-269. https://doi.org/10.1016/j.buildenv.2015.11.026.

Maleetipwan-Mattsson, P., Laike, T., \& Johansson, M. (2017). The effects of user interface designs on lighting use. Journal of Engineering, Design and Technology, 15(1), 58-78. https://doi.org/10.1108/JEDT-06-2015-0040.

Moezzi, M., \& Janda, K. B. (2014). From "if only" to "social potential" in schemes to reduce building energy use. Energy Research and Social Science, 1, 30-40. https://doi. org/10.1016/j.erss.2014.03.014.

Moser, G. (2009). Quality of life and sustainability: toward person-environment congruity. Journal of Environmental Psychology, 29(3), 351-357. https://doi.org/10.1016/j. jenvp.2009.02.002.

Nasar, J. L. (2008). Assessing perceptions of environments for active living. American Journal of Preventive Medicine, 34(4), 357-363. https://doi.org/10.1016/j. amepre.2008.01.013.

Neij, L., Sandin, S., Benner, M., Johansson, M., \& Mickwitz, P. (2021). Bolstering a transition for a more sustainable energy system: a transformative approach to evaluations of energy efficiency in buildings. Energy Research \& Social Science, 72. https://doi.org/10.1016/j.erss.2020.101864.

Nilsson, A., Bergstad, C. J., Thuvander, L., Andersson, D., Andersson, K., \& Meiling, P. (2014). Effects of continuous feedback on households' electricity consumption: Potentials and barriers. Applied Energy, 122, 17-23. https://doi. org/10.1016/j.apenergy.2014.01.060.

Nilsson, A., Andersson, K., \& Bergstad, C. J. (2015). Energy behaviors at the office: An intervention study on the use of equipment. Applied Energy, 146, 434-441. https://doi. org/10.1016/j.apenergy.2015.02.045.

Nilsson, A., Stoll, P., \& Brandt, N. (2017). Assessing the impact of real-time price visualization on residential electricity consumption, costs, and carbon emissions. Resources, Conservation and Recycling, 124, 152-161. https://doi. org/10.1016/j.resconrec.2015.10.007.

Nilsson, A., Lazarevic, D., Brandt, N., \& Kordas, O. (2018a). Household responsiveness to residential demand response strategies: Results and policy implications from a swedish field study. Energy Policy, 122, 273-286. https://doi. org/10.1016/j.enpol.2018.07.044.

Nilsson, A., Wester, M., Lazarevic, D., \& Brandt, N. (2018b). Smart homes, home energy management systems and realtime feedback: Lessons for influencing household energy consumption from a Swedish field study. Energy and Buildings, 179, 15-25. https://doi.org/10.1016/j. enbuild.2018.08.026.

Palm, J. (2010). The public-private divide in household behavior: How far into home can energy guidance reach? Energy Policy, 38(6), 2858-2864. https://doi.org/10.1016/j. enpol.2010.01.018.

Palm, J., \& Reindl, K. (2016). Understanding energy efficiency in Swedish residential building renovation: a practice theory approach. Energy Research and Social Science, 11, 247255. https://doi.org/10.1016/j.erss.2015.11.006.

Palm, J., Eidenskog, M., \& Luthander, R. (2018). Sufficiency, change, and flexibility: Critically examining the energy consumption profiles of solar PV prosumers in Sweden. Energy Research and Social Science, 39, 12-18. https://doi. org/10.1016/j.erss.2017.10.006.

Righer Hansen, A. (2018). "Sticky" energy practices: the impact of childhood and early adulthood experience on later energy consumption practices. Energy Research and Social Science, 46, 125-139. https://doi.org/10.1016/j.erss.2018.06.013.

Righer Hansen, A., Gram-Hanssen, K., \& Knudsen, H. N. (2018). How building design and technologies influence heat-related habits. Building Research \& Information, 46(1), 83-98. https://doi.org/10.1080/09613218.2017.1335477.

Robson, C. (2011). Real world research: a resource for users of social research methods in applied settings (3rd ed.). Chichester, West Sussex: Wiley.

Rohdin, P., Molin, A., \& Moshfegh, B. (2014). Experiences from nine passive houses in Sweden - indoor thermal environment and energy use. Building and Environment, 71, 176-185. https://doi.org/10.1016/j.buildenv.2013.09.017.

Salo, M. M., Nissinen, A., Lilja, R., Olkanen, E., O’Neill, M., \& Uotinen, M. (2016). Tailored advice and services to enhance sustainable household consumption in Finland. Journal of Cleaner Production, 121, 200-207. https://doi.org/10.1016/j. jclepro.2016.01.092.

Sandin, S., Neij, L., \& Mickwitz, P. (2019). Transition governance for energy efficiency - insights from a systematic review of Swedish policy evaluation practices. Energy. Sustainability and Society, 9(1), 17. https://doi.org/10.1186/s13705-0190203-6. 
Schuitema, G., \& Bergstad Jakobsson, C. (2013). Acceptability of environmental policies. In L. Steg, A. E. van den Berg, \& J. I. M. de Groot (Eds.), Environmental psychology an introduction. The British Psychological Society and John Wiley \& Sons.

Schwarz, S. (1977). Normative influences on altruism. In: L. Berkowitz (ed.), Advances in Experimental Social Psychology (Vol. 10, pp. 221-279). New York: Academic Press.

Schweber, L., \& Leiringer, R. (2012). Beyond the technical: a snapshot of energy and buildings research. Building Research and Information, 40(4), 481-492. https://doi. org/10.1080/09613218.2012.675713.

Shove, E. (2010). Beyond the ABC: climate change policy and theories of social change. Environment and Planning A, 42(6), 1273-1285. https://doi.org/10.1068/a42282.

Siggelsten, S., \& Olander, S. (2013). Individual metering and charging of heat and hot water in Swedish housing cooperatives. Energy Policy, 61, 874-880. https://doi.org/10.1016/j. enpol.2013.06.083.

Skjølsvold, T. M., \& Ryghaug, M. (2015). Embedding smart energy technology in built environments: A comparative study of four smart grid demonstration projects. Indoor and Built Environment, 24(7), 878-890. https://doi.org/10.1177 /1420326X15596210.

Skjølsvold, T. M., Jørgensen, S., \& Ryghaug, M. (2017). Users, design and the role of feedback technologies in the Norwegian energy transition: an empirical study and some radical challenges. Energy Research and Social Science, 25, 1-8. https://doi.org/10.1016/j.erss.2016.11.005.

Sovacool, B. K. (2014). What are we doing here? analyzing fifteen years of energy scholarship andproposing a social science research agenda. Energy Research and Social Science, 1, 129. https://doi.org/10.1016/j.erss.2014.02.003.

Sovacool, B. K., Axsen, J., \& Sorrell, S. (2018). Promoting novelty, rigor, and style in energy social science: towards codes of practice for appropriate methods and research design. Energy Research and Social Science, 45, 12-42. https://doi.org/10.1016/j.erss.2018.07.007.

Steg, L. (2008). Promoting household energy conservation. Energy Policy, 36(12), 4449-4453. https://doi.org/10.1016 j.enpol.2008.09.027.

Steg, L., \& Vlek, C. (2009). Encouraging pro-environmental behaviour: An integrative review and research agenda. Journal of Environmental Psychology, 29(3), 309-317. https://doi.org/10.1016/j.jenvp.2008.10.004.

Steg, L., Perlaviciute, G. \& van der Wer, E. (2015). Understanding the human dimensions of a sustainable energy transition.
Frontiers in Psychology. doi: https://doi.org/10.3389 /fpsyg.2015.00805

Stern, P. C. (2000). Toward a coherent theory of environmentally significant behavior. Journal of Social Issues, 56(3), 407424.

Stern, P. C. (2014). Individual and household interactions with energy systems: Toward integrated understanding. Energy Research and Social Science, 1, 41-48. https://doi. org/10.1016/j.erss.2014.03.003.

Stern, P. C. (2017). How can social science research become more influential in energy transitions? Energy Research \& Social Science, 26, 91-95. https://doi.org/10.1016/j. erss.2017.01.010.

Stragier, J., Hauttekeete, L., De Marez, L., \& Brondeel, R. (2012). Measuring energy-efficient behavior in households: The development of a standardized scale. Ecopsychology, 4(1), 6471. doi:https://doi.org/10.1089/eco.2012.0026

Vassileva, I., Oldare, M., Wallin, F., \& Dahlquist, F. (2012a). The impact of consumers' feedback preferences on domestic electricity consumption. Applied Energy, 93, 575-582. https://doi.org/10.1016/j.apenergy.2011.12.067.

Vassileva, I., Wallin, F., \& Dahlquist, E. (2012b). Analytical comparison between electricity consumption and behavioral characteristics of Swedish households in rented apartments. Applied Energy, 90(1), 182-188. https://doi.org/10.1016/j. apenergy.2011.05.031.

Vassileva, I., Dahlquist, E., Wallin, F., \& Campillo, J. (2013). Energy consumption feedback devices' impact evaluation on domestic energy use. Applied Energy, 106, 314-320. https://doi.org/10.1016/j.apenergy.2013.01.059.

Vlasova, L., \& Gram-Hanssen, K. (2014). Incorporating inhabitants everyday practices into domestic retrofits. Building Research and Information, 42(4), 512-524. https://doi. org/10.1080/09613218.2014.907682.

Westskog, H., Winther, T., \& Sæle, H. (2015). The effects of inhome displays-revisiting the context. Sustainability, 7(5), 5431-5451. https://doi.org/10.3390/su7055431.

Wilson, C., \& Chatterton, T. (2011). Multiple models to inform climate change policy: A pragmatic response to the 'beyond the ABC' debate. Environment and Planning A, 43, 27812787.

Zalejska-Jonsson, A. (2012). Evaluation of low-energy and conventional residential buildings from occupants' perspective. Building and Environment, 58(135-144), 2012.

Publisher's note Springer Nature remains neutral with regard to jurisdictional claims in published maps and institutional affiliations. 